\title{
Karyomorphological Studies in Asiatic Cottons I. Karyotypic analysis of species and races of Asiatic cottons based on chromatin content
}

\author{
M. N. Gennur, S. N. Kadapa, A. F. Habib and J. V. Goud \\ Department of Agricultural Botany, \\ University of Agricultural Sciences, Dharwad, \\ Karnataka, 580005 India
}

Accepted September 28, 1986

The species considered for the studies, Gossypium herbaceum and Gossypium arboreum belong to natural order Malvales, family Malvaceae, subfamily Hibisceae and section Herbacea. $G$. herbaceum has been divided into five races viz., africanum, acerifolium, persicum, kultjianum, wightianum and $G$. arboreum has been classified into six races viz., saudanense, indicum, burmanicum, sinense, bengalense, cernuum. The karyomorphological studies in Asiatic cottons has been divided into two parts. Part I deals with the chromatin content of the genome, and part II deals with the nucleolar chromosomes and symmetry of the karyotype. Two races of $G$. herbaceum viz., persicum and wightianum and two races of $G$. arboreum viz., indicum and bengalense are used in the studies.

\section{Materials and methods}

The cotton seeds kindly supplied by the Senior Scientist (Cotton), ARS, Dhawrad were put for germination in the germination box. The actively growing root tips of $0.5 \mathrm{~cm}$ were excised at 1.0 PM and pretreated with $0.002 \mathrm{M}$ 8-hydroxyquinoline for 4 hours and were then fixed in acetic alcohol $(1: 3)$ for 24 hours. The root tips taken from the fixative were put in $5 \%$ pectinase solution for one hour. Then the root tips were hydrolysed in $1 \mathrm{~N} \mathrm{HCl}$ with $1.5 \%$ acetocarmine in the proportion of $1: 5$ drops in a watch glass, by gently heating over the spirit lamp flame till the vapour were seen. The hydrolysed root tips were squashed in $1.5 \%$ acetocarmine. The total length of all the chromosomes of a haploid component has been taken as the absolute length. The statistical comparisons were made by applying ' $t$ ' test. In the idiograms the secondary constrictions are differentiated from satellites by leaving blank in the secondary constriction chromosomes.

\section{Results and discussion}

The karyotypic analysis of $G$. herbaceum, G. arboreum and their races was made on the basis of largest chromosome length, smallest chromosome length and absolute length. The smallest chromosome length of G. herbaceum and G. arboreum was $1.713 \mu$ and $1.322 \mu$ respectively. The race wightianum had shorter smallest chromosome length $(1.408 \mu)$ compared to race persicum $(1.830 \mu)$ in $G$. herbaceum (Table 1) while $G$. arboreum race bengalense had shorter smallest chromosome length $(1.269 \mu)$ compared to race indicum $(1.385 \mu)$ (Table 2).

The largest chromosome length of $G$. herbaceum and $G$. arboreum was $2.814 \mu$ and $2.319 \mu$ respectively. The largest chromosome length of race perscium $(2.914 \mu)$ was greater than that of the race wightianum $(2.555 \mu)$ in $G$. herbaceum (Table 1). In G. arboreum the largest chromosome length of race indicum $(2.402 \mu)$ was greater than that of the race bengalense $(2.248 \mu)$ 
(Table 2).

Absolute chromosome length of $G$. herbaceum was $29.547 \mu$ and that of $G$. arboreum was $23.827 \mu$. In case of races persicum and wightianum of $G$. herbaceum it was $30.516 \mu$ and $27.025 \mu$ respectively while in case of indicum and bengalense of $G$. arboreum it was $25.060 \mu$ and $22.770 \mu$ respectively (Tables 1,2 ).

From the statistical analysis it was clear that the reduction in absolute chromosome length from $G$. herbaceum to $G$. arboreum at species level and from persicum to wightianum and indicum to bengalense at racial level was significant (Tables $1,2,3$ ).

Table 1. Racial differences of chromosome length in Gossypium herbaceum

\begin{tabular}{|c|c|c|c|}
\hline $\begin{array}{l}\text { Rece/Culture } \\
\text { G. herbaceum }\end{array}$ & $\begin{array}{c}\text { Smallest } \\
\text { chromosome } \\
(\mu)\end{array}$ & $\begin{array}{c}\text { Largest } \\
\text { chromosome } \\
(\mu)\end{array}$ & $\begin{array}{c}\text { Absolute } \\
\text { length } \\
(\mu)\end{array}$ \\
\hline \multicolumn{4}{|l|}{ Race persicum } \\
\hline 1449 & 1.890 & 3.265 & 34.401 \\
\hline 5497 & 1.875 & 3.250 & 34.310 \\
\hline 6455 & 1.869 & 3.243 & 34.196 \\
\hline DM 125 & 1.945 & 2.830 & 30.684 \\
\hline SM 14 & 2.000 & 2.687 & 30.516 \\
\hline SM 150 & 1.937 & 2.812 & 30.371 \\
\hline SM 43 & 1.930 & 2.890 & 30.327 \\
\hline SM 81 & 1.725 & 2.940 & 29.152 \\
\hline SM 41 & 1.625 & 2.937 & 28.997 \\
\hline SM 141 & 1.700 & 2.824 & 28.686 \\
\hline SM 73 & 1.800 & 2.705 & 28.662 \\
\hline SM 143 & 1.750 & 2.750 & 28.289 \\
\hline SM 88 & 1.750 & 2.750 & 28.123 \\
\hline Range & $1.625-2.000$ & $2.687-3.265$ & $28.123-34.401$ \\
\hline Average of race & 1.830 & 2.914 & $30.516^{*}$ \\
\hline Variance $\left(\sigma^{2}\right)$ & - & - & 5.396 \\
\hline S. Em. \pm & - & - & 0.644 \\
\hline \multicolumn{4}{|l|}{ Race wightianum } \\
\hline Jayadhar & 1.187 & 2.562 & 27.506 \\
\hline R $51-238$ & 1.480 & 2.715 & 27.365 \\
\hline $\operatorname{MDS} 42$ & 1.499 & 2.500 & 26.936 \\
\hline DB 3-12 & 1.500 & 2.625 & 26.810 \\
\hline $25-B-6$ & 1.375 & 2.375 & 26.509 \\
\hline Range & $1.187-1.500$ & $2.375-2.715$ & $26.509-27.506$ \\
\hline Average of race & 1.408 & 2.555 & 27.025 \\
\hline Variance $\left(\sigma^{2}\right)$ & - & - & 0.166 \\
\hline S. Em. \pm & - & - & 0.182 \\
\hline Calculated $\mathrm{t}$ & - & - & 5.123 \\
\hline Table t & - & 一 & 2.220 \\
\hline Average of species & 1.713 & 2.814 & 29.547 \\
\hline
\end{tabular}

* persicum significantly differs from wightianum at $5 \%$ level.

Mikhailova (1936) did not notice any appreciable difference in the size of chromosome and concluded that the karyotypes of Asiatic cottons were substantially the same but on the contrary in the present investigation lot of variation was observed (Plate 1). With regard to absolute length, the present findings agreed with the findings of Tutajuk and Sadytiova (1967) that the somatic chromosomes of $G$. herbaceum were relatively larger compared to $G$. arboreum but the statement of Skovsted (1933) that the somatic chromosomes of G. arboreum were of equal sizes did not hold true since there was lot of variation. The present investigation did not 
support the analysis of Jacob $(1941,1942)$ that the shortest chromosomes of all the herbaceum types (races) were nearly equal since there was variation amongst the races of $G$. herbaceum with respect to shortest chromosomes (Plate 1).

The genetic and evolutionary significance of heterochromatin has been reported by Darlington and Mather (1950). They pointed out that in some cases the loss of heterochromatin

Table 2. Racial differences of chromosome length in Gossypium arboreum

\begin{tabular}{lccc}
\hline $\begin{array}{l}\text { Race/Culture } \\
\text { G. arboreum }\end{array}$ & $\begin{array}{c}\text { Smallest } \\
\text { chromosome } \\
(\mu)\end{array}$ & $\begin{array}{c}\text { Largest } \\
\text { chromosome } \\
(\mu)\end{array}$ & $\begin{array}{c}\text { Absolute } \\
\text { length } \\
(\mu)\end{array}$ \\
\hline Race indicum & & & \\
1187 & 1.562 & 2.325 & 25.779 \\
853 & 1.250 & 2.499 & 25.621 \\
860 & 1.437 & 2.437 & 25.184 \\
1042 & 1.562 & 2.525 & 24.834 \\
824 & 1.437 & 2.375 & 24.821 \\
875 & 1.062 & 2.250 & 24.122 \\
Range & $1.062-1.562$ & $2.250-2.525$ & $24.122-25.779$ \\
Average of race & 1.385 & 2.402 & $25.060^{*}$ \\
Variance $\left(\sigma^{2}\right)$ & - & - & 0.367 \\
S. Em. \pm & - & - & 0.247 \\
race bengalense & & & \\
LD 124 & 1.312 & 2.250 & 25.185 \\
LD 132 & 1.500 & 2.312 & 23.185 \\
Lohit & 1.337 & 2.350 & 23.123 \\
G 27 & 1.150 & 2.412 & 22.810 \\
LD 133 & 1.087 & 2.162 & 22.372 \\
LD 135 & 1.250 & 2.125 & 21.373 \\
HD 11 & 1.250 & 2.125 & 21.340 \\
Range & $1.087-1.500$ & $1.125-2.412$ & $21.340-25.185$ \\
Average of race & 1.269 & 2.248 & 22.770 \\
Variance $\left(\sigma^{2}\right)$ & - & - & 1.714 \\
S. Em \pm & - & - & 0.495 \\
Calculated t & - & - & 3.930 \\
Table t & - & 2.319 & 2.201 \\
\hline Average of species & 1.322 & & 23.827 \\
\hline indign & - & - &
\end{tabular}

* indicum significantly differs from bengalense at $5 \%$ level.

Table 3. Comparison of $G$. herbaceum and $G$. arboreum with respect to absolute length

\begin{tabular}{lcc}
\hline \hline & G. herbaceum & G. arboreum \\
\hline Average absolute length $(\mu)$ & $29.547^{*}$ & 23.827 \\
Variance & 6.079 & 2.236 \\
S. Em $t$ & 0.581 & 0.414 \\
Calculated $t$ & 7.486 & - \\
Table $t$ & 1.119 & -
\end{tabular}

* herbaceum signiflcantly differs from arboreum at $5 \%$ level.

segments could be tolerated by the species and it rather adds to their selection value. Sen and Tiwari (1966) noticed changes in the chromosome size and subsequent alterations in the karyotypes of cultures of Pisum sativum which was due to loss of heterochromatic material. Mursal and Endrizzi (1976) observed increased ' $A$ ' genome size compared to ' $D$ ' genome size in G. hirsutum due to the presence of more repetitive DNA in 'A' genome. Edwards (1977) 
noticed that absolute length of $G$. herbaceum race africanum which is the wild form of Asiatic cottons, was $33.06 \mu$. In the present study absolute length of races persicum and wightianum of $G$. herbaceum was $30.516 \mu$ and $27.025 \mu$ respectively. Hence, it is an indication of the reduction in chromosome size from race africanum to persicum and wightianum due to removal of repetitive DNA in the course of evolution.
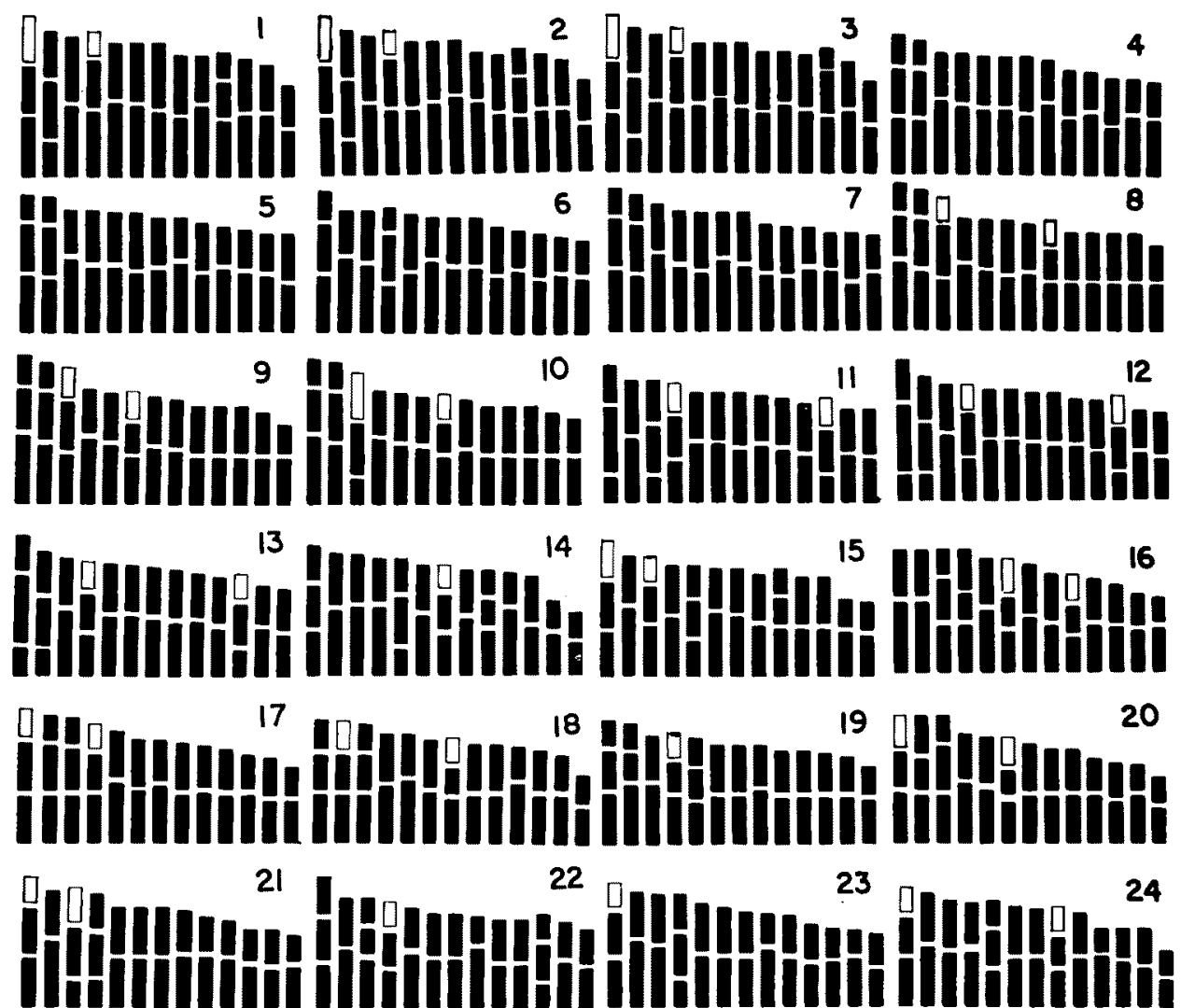

21

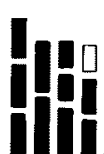

22

23

पn 24

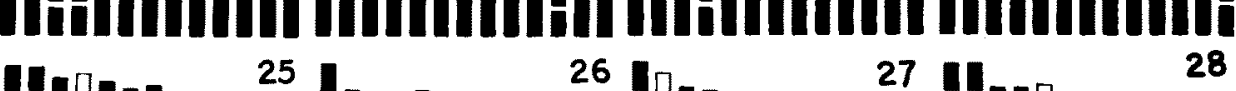

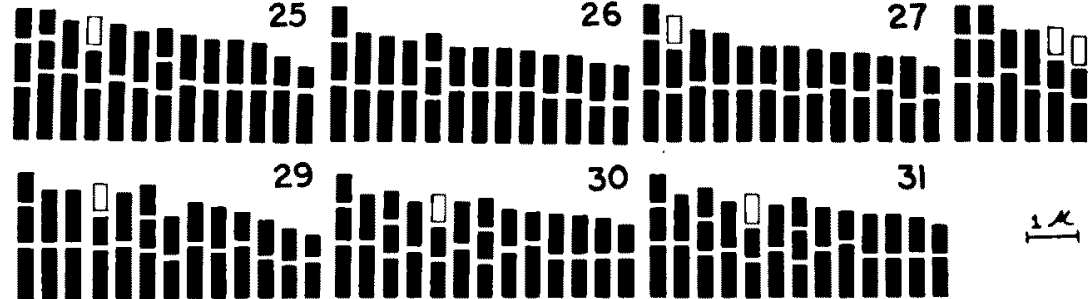

Plate 1. Figs. 1-31. Idiograms of cultures of races persicum (1-13), wightianum (14-18), indicum (19-24) and bengalense (25-31). 1, 1449; 2, 5497; 3, 6455; 4, DM 125; 5, SM 14; 5, SM 14; 6, SM $150 ; 7$, SM 43; 8, SM 81 ; 9, SM 41; 10, SM 141; 11, SM 73; 12, SM 143; 13, SM 88; 14, Jayadhar; 15, R 51-238; 16, MDS 42; 17, DB 3-12; 18, 2 5-B-6; 19, 1187; 20, 853; 21, 860; 22, 1042; 23, 824; 24, 875; 25, LD 124; 26, LD 132; 27, Lohit; 28, G 27; 29, LD 133; 30, LD 135; 31, HD 11.

In the study of largest, smallest and absolute length it was noticed that there was reduction in the size of the chromosome from species to species and race to race (Tables 1,2). Differences in absolute chromosome size reflects different amounts of gene duplication either in tandem fashion or through polytene multiplication of chromonemata and also that the species having greater chromatin length were supposed to be primitive where as species with lesser chromatin 
length were treated as advanced (Stebbins 1971). Therefore, amongst the two species, $G$. herbaceum is primitive compared to G. arboreum. Among two races of G. herbaceum, persicum
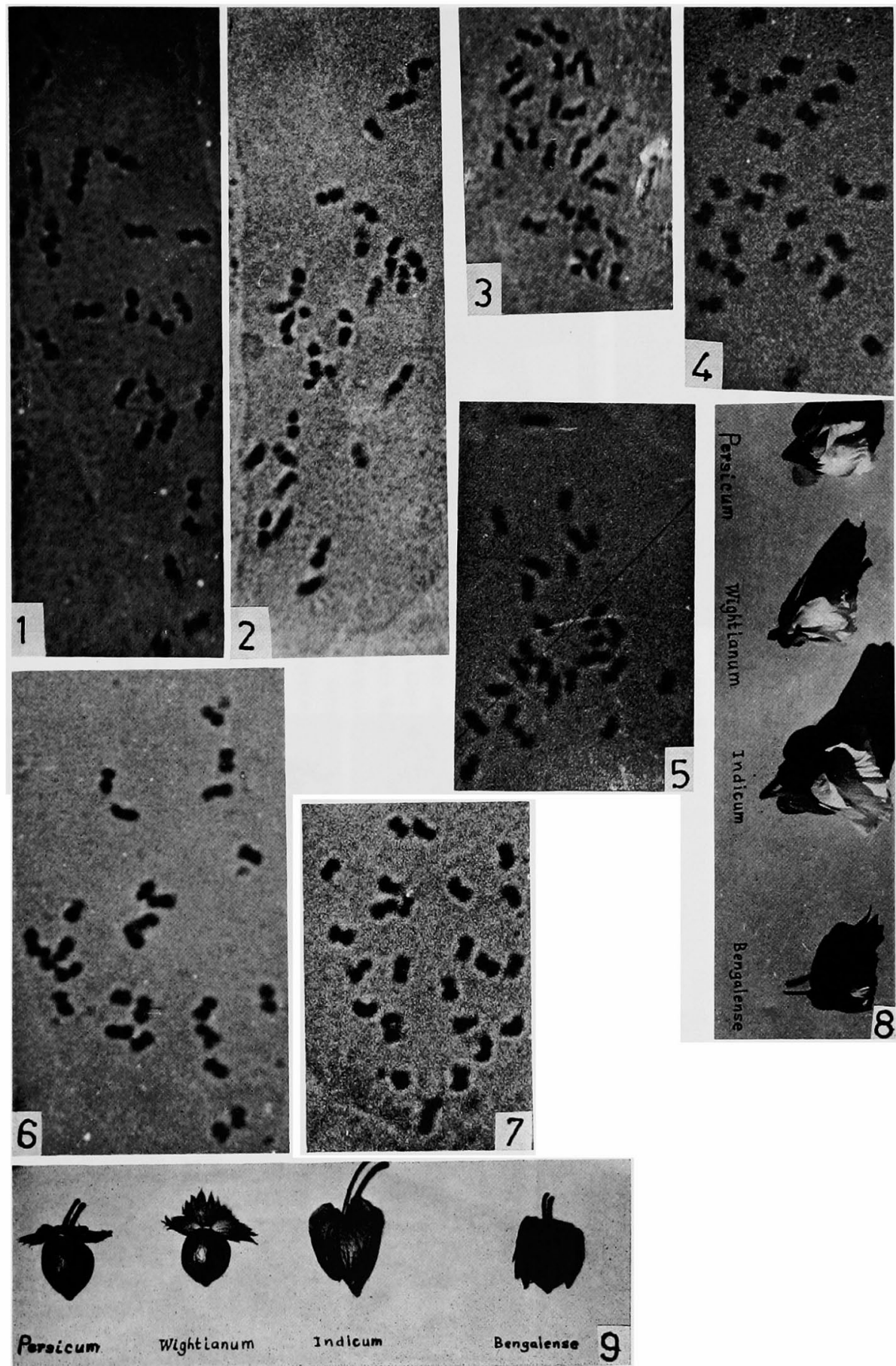

Plate 2. Figs. 1-9. Metaphase plates of cultures of races persicum $(1,5497 ; 2$, SM 88), wightianum $(3,2$ 5-B-6), indicum $(4,860 ; 5,1042 ; 6,824 ; 7,875$.) and flowers $(8)$ and bolls $(9)$ of all races. 
is relatively primitive compared to wightianum and among two races of $G$. arboreum, indicum is primitive compared to bengalense.
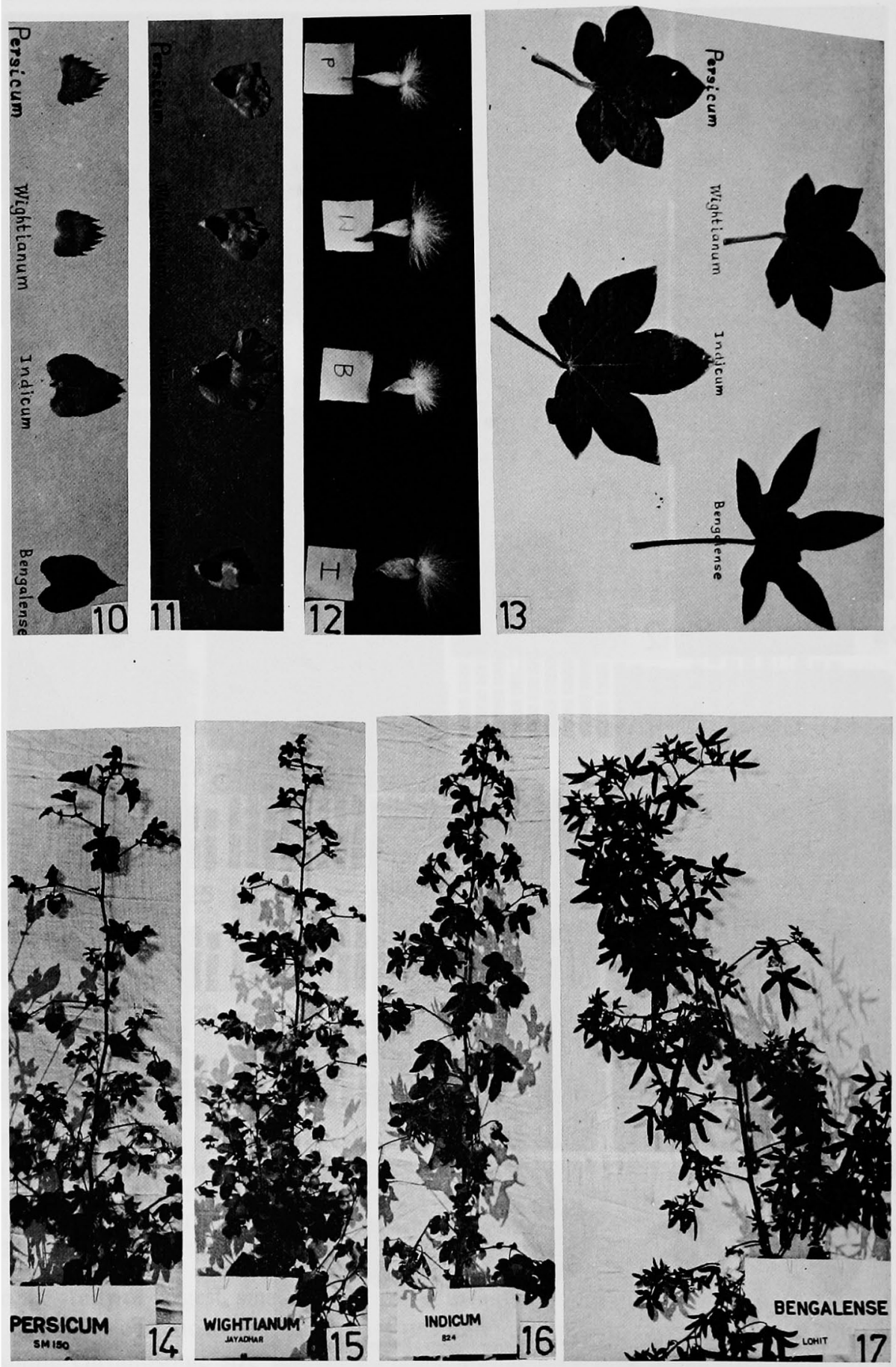

Plate 3. Figs. 10-13. Bracteoles, petals, lint and leaves of races persicum, wightianum, indicum and bengalense. Figs. 14-17. Plants of races persicum, wightianum, indicum and bengalense. 


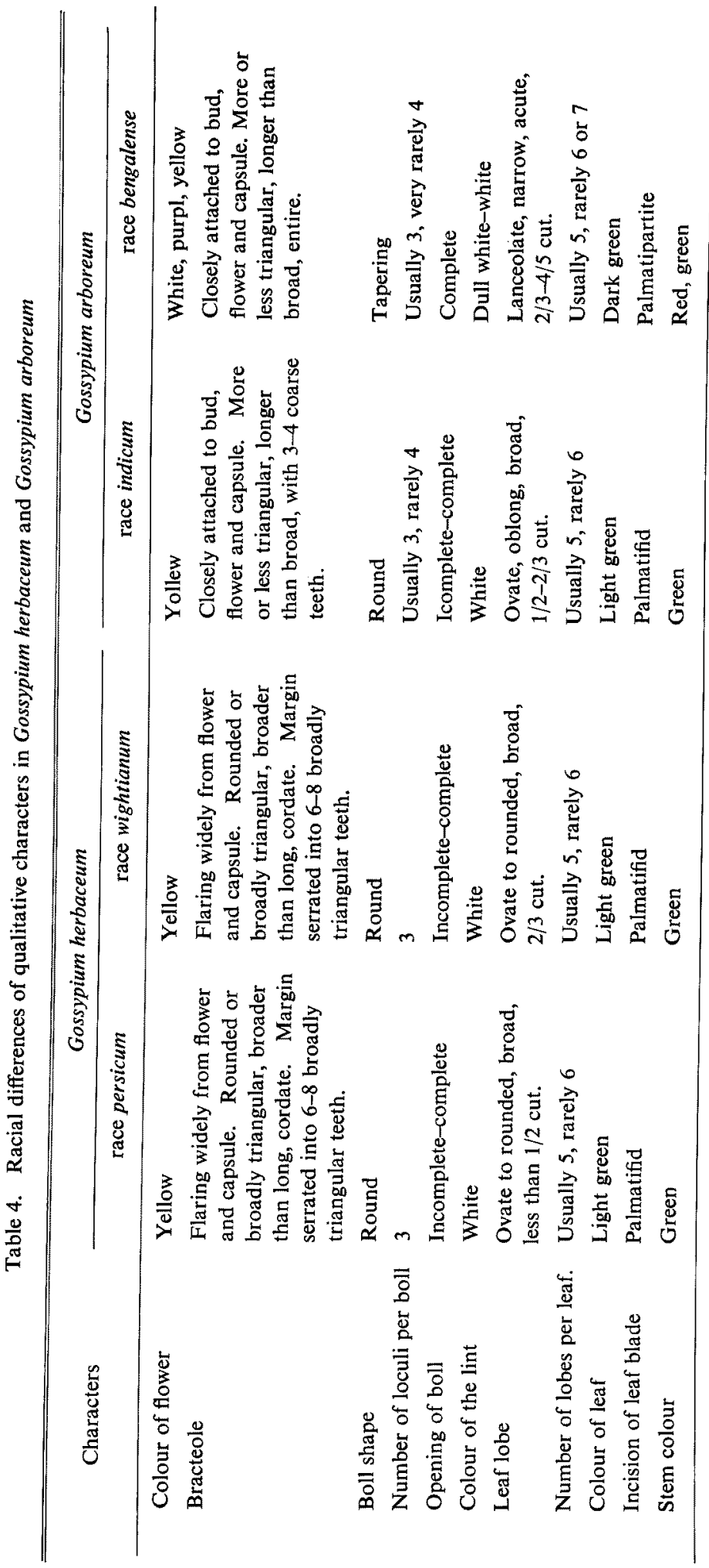


From the present karyotypic analysis it has been concluded that $G$. arboreum has evolved as a result of loss of redundant DNA from $G$. herbaceum in the course of evolution in addition to the major change of one translocation as indicated by Gerstel (1953) which has been confirmed by Gennur et al. (1986).

The present findings are in line with the earlier findings of Babcock and Cameron (1934) and Stebbins (1950) in different plant species that there was change in plant habit as there was reduction in absolute chromosome size, since $G$. herbaceum race africanum with perennial habit had $33.06 \mu$ absolute length (Edwards 1977) where as races persicum and wightianum had $30.516 \mu$ and $27.025 \mu$ respectively with annual habits.

Though there was phylogentic reduction in the absolute chromosome size from persicum to wightianum in $G$. herbaceum there was no difference between both the races with respect to qualitative characters (Plate 2, Figs. 8, 9; Plate 3) (Table 3). This is similar to the case of Taraxacum wherein the reduction in absolute chromosome size has not always been accompanied by the morphological specialisation like decrease in the size of floral parts or change in the colour of leaves or any other plant part (Stebbins 1950). Reduction in absolute chromosome size was also observed in the race of $G$. arboreum, since indicum had absolute chromosome size of $25.060 \mu$ and begnalense had $22.770 \mu$. In G. arboreum the reduction in absolute chrosome size of races was associated with drastic morphological variations in the plant parts with regard to qualitative characters. The cultures of indicum had light green palmatifid leaves and yellow flowers where as cultures of bengalense had dark green palmatipartite leaves, smaller flowers with different colours like yellow, pink and white. Apart from it there were many acute differences between indicum and bengalense plant habits (Plate 2, Figs. 8, 9; Plate 3) (Table 3).

\section{Summary}

Karyotypic analysis of Gossypium herbaceum (races persicum and wightianum) and $G$. arboreum (race indicum and bengalense) with two races in each species has been made on the basis of smallest, largest and absolute chromosome length. It is concluded that at species level $G$. herbaceum is primitive to $G$. arobreum and at racial level parsicum is primitive to wightianum in $G$. herbaceum and indicum is primitive to bengalense in G. arboreum

\section{References}

Babcock, C. G. and Cameron, D. R. 1934. Chromosomes and phylogeny in Crepis II. The relationship of 108 species. Univ. of Calif. Publ. Agri. Sci. 6: 287-324.

Darlington, C. D. and Mather, K. 1950. Genes, Plants and People. Allen and Unwin Ltd. London, 34-46.

Edwards, G. A. 1977. The karyotype of Gossypium herbaceum I. Caryologia 30(3): 369-374.

Gennur, M. N., Habib, A. F., Kadapa, S. N. and Goud, J. V. 1986. Cytogenetic studies in interspecific and intraspecific hybrids of Gossypium herbaceum and Gossypium arboreum. Caryologia 39(1): 65-68.

Gerstel, D. U. 1953. Chromosomal translocations in interspecific hybrids of the genus Gossypium. Evolution 7: 234-244.

Jacob, K. T. 1941. Preliminary observations on the chromosome morphology in Asiatic cottons with special reference to their phylogeny and inter-relationships. 2nd Conf. Cotton Gr. Probl. India, I.C.C.C, Bonbay, $42-45$.

- 1942. Studies in cotion IV. Morphology of somatic chromosomes in eight types of Asiatic cottons. Trans. Bose Res. Inst. 15: 17-27.

Mikhailova, K. A. 1936. Resume results objects Res. work Cent. Br. Sta. Soyuznikhi. Tashkent 52: (PBA 8: 169).

Mursal, I. E. J. and Endrizzi, J. E. 1976. A re-examination of the diploid like meiotic behaviour of polyploid cotton. Theor. Appl. Genet. 47: 171-178. 
Sen, S. K. and Tiwari, C. B. 1966. Karyotype studies in Pisum sativum. Nucleus 9: 173-176.

Skovsted, A. 1933. Cytological studies in cotton I. The mitosis cand meiosis in diploid and triploid Asiatic cottons. Ann. Bot. 47: 227-251.

Stebbins, G. L. 1950. Variation and Evolution in Plants. Oxford Book Company, 466-467.

- 1971. Chromosomal Evolution in Higher Plants. Edward Arnold Publ. Ltd., London, 49-113.

Tutajuk, V. H. and Sadytiova, L. D. 1967. Morphology of chromosomes in somatic cells of some species of cotton. Merizeler Azarb. SSR Elmeler Akad. 23(5): 59-63. 